\title{
Efficacy of Pramipexole for Treatment of Apathy in Parkinson's Disease
}

\author{
Hiroaki Oguro ${ }^{*}$, Katsuhiko Kadota1, Masaki Ishihara ${ }^{2}$, Kazunori Okada ${ }^{3}$, \\ Shuhei Yamaguchi ${ }^{1}$ \\ ${ }^{1}$ Department of Neurology, Faculty of Medicine, Shimane University, Shimane, Japan \\ ${ }^{2}$ Department of Neurology, Tokyo Metropolitan Health and Medical Treatment Corporation, Toshima Hospital, \\ Tokyo, Japan \\ ${ }^{3}$ Department of Neurology, Ohda Silver Clinic, Shimane, Japan \\ Email: oguro@med.shimane-u.ac.jp
}

Received 9 July 2014; revised 31 July 2014; accepted 11 August 2014

Copyright (C) 2014 by authors and Scientific Research Publishing Inc.

This work is licensed under the Creative Commons Attribution International License (CC BY).

http://creativecommons.org/licenses/by/4.0/

(c) (i) Open Access

\section{Abstract}

Background: Apathy occurs frequently in patients with Parkinson's disease (PD), and has a negative impact on activities of daily living through loss of motivation. Pramipexole (PPX), which shows preferential affinity for D3 dopamine receptor in the mesolimbic system, is thought to influence mood and motivation. Therefore, we conducted an open-label case-control study to examine the effect of PPX on apathy in PD. Methods: We studied 36 PD patients (mean age, 70.4 \pm 8.1 years), who had been treated only with L-DOPA. PPX was added to L-DOPA treatment in 24 patients (PPX group) and other 12 patients continued with L-DOPA alone (non-PPX group). The study period was 8 weeks. Apathy was assessed using the revised apathy scale for Japanese. Motor function was assessed with part III of the Unified Parkinson's Disease Rating Scale (UPDRS). Results: Seventeen of 36 patients $(47 \%)$ were diagnosed as having apathy. In the PPX group, apathy scale significantly improved from 17.3 to 13.8 at week $8(p<0.05)$. Motor function also improved significantly from 16.1 to 7.6 at week $8(p<0.0001)$. In the non-PPX group, apathy scale and UPDRS both showed no change during the study period. There was no correlation between changes in apathy scale and UPDRS in either the PPX or non-PPX group. Conclusion: PPX may be effective for treating apathy as well as motor dysfunction in PD.

\section{Keywords}

Pramipexole, Apathy, Parkinson's disease, Depression, UPDRS

\footnotetext{
${ }^{*}$ Corresponding author.
}

How to cite this paper: Oguro, H., Kadota, K., Ishihara, M., Okada, K. and Yamaguchi, S. (2014) Efficacy of Pramipexole for Treatment of Apathy in Parkinson's Disease. International Journal of Clinical Medicine, 5, 885-889. 


\section{Introduction}

Parkinson's disease (PD) is caused by progressive degeneration of dopamine-producing cells in the substantia nigra, and has been treated with L-dopa and dopamine receptor agonist. Pramipexole (PPX) has dopamine agonist activity at presynaptic and postsynaptic dopamine receptors belonging to the $\mathrm{D}_{2}$-like family and is effective in treating Parkinson's disease, showing high affinity for dopamine $\mathrm{D}_{3}$ receptor [1].

Apathy has a negative impact on activities of daily living owing to loss of motivation, concern, interest and emotional response [2]. It has been associated with executive dysfunction, impaired emotional processing and impaired decision-making, and it causes flattened affect and decrease of goal-directed behavior [3]. It can be a substantial burden for caregivers and may occur as a part of the symptoms of depression or dementia [2]. Affective problems are the most frequent non-motor symptoms in Parkinson's disease and apathy occurs in $17 \%$ to $70 \%$ of patients with PD [4]. However, there is only one report investigating the effectiveness of a $\mathrm{D}_{2} / \mathrm{D}_{3}$ receptor agonist, piribedil, on apathy as a primary outcome in PD [5]. Here, we studied the clinical efficacy of PPX on apathy in PD using the self-assessed apathy scale.

\section{Patients and Methods}

Thirty-six patients with PD (11 males and 25 females, mean age = $70.4 \pm 8.1$ (SD) years old) participated in this study. The length of illness was $52 \pm 48$ (SD) months. They were divided into two groups at random; 24 patients with L-DOPA, $241.6 \pm 112.9$ (SD) mg/day plus PPX medication (the PPX group) and 12 patients with only LDOPA medication, $431.8 \pm 202.8$ (SD) mg/day (non-PPX group). Clinical characteristics are summarized in Table 1. All subjects gave informed consent in accordance with the protocol of the Shimane University research ethics committees, the open label study and the Declaration of Helsinki. All subjects underwent neurological examination and their total score on the unified Parkinson's disease rating scale (UPDRS) Part III (motor function) was estimated. Apathy was evaluated by means of the modified apathy scale (revised version in Japanese [6]). Mini-mental state examination (MMSE) was also conducted in all participants to adjust memory function between the two groups.

Participants were restricted to those who took only L-DOPA, because other dopamine receptor agonists, amantadine and selegiline, might influence apathy in PD [7]. In the PPX group, PPX was added to L-DOPA. PPX was started at $0.25 \mathrm{mg} /$ day $(0.125 \mathrm{mg}$ two times per day) for the first 2 weeks, $0.5 \mathrm{mg} / \mathrm{day}(0.25 \mathrm{mg}$ two times per day) for the second 2 weeks, $1 \mathrm{mg} /$ day ( $0.5 \mathrm{mg}$ two times per day) for the third 2 weeks, and then 1.5 $\mathrm{mg}$ /day (0.5 mg three times per a day) as the maximum dose. Clinical assessment was performed twice; intermediate assessment at the end of week 4 and the final assessment at the end of week 8 . The non-PPX group continued to take the same dosage of L-DOPA during the study period.

\section{Statistical Analysis}

The Wilcoxon signed ranks test was used for comparison of apathy scales and UPDRS before and after administration of PPX. The Spearman correlation coefficient was used to calculate the relationship between changes in

Table 1. Baseline characteristics of the PPX groups, non-PPX groups and all subjects.

\begin{tabular}{ccccc}
\hline & PPX groups $(\mathrm{n}=24)$ & Non-PPX groups $(\mathrm{n}=12)$ & Total $(\mathrm{n}=36)$ & $\mathrm{P}$ \\
\hline Mean age (years) & $70.9 \pm 7.8$ & $69.3 \pm 8.9$ & $70.4 \pm 8.1$ & $0.4805^{*}$ \\
Male (\%) & $4(33.2 \%)$ & $7(29.2 \%)$ & $11(30.5 \%)$ & $0.9999^{\S}$ \\
Length of illness (months) & $49.5 \pm 50.9$ & $48.7 \pm 42.0$ & $49.3 \pm 47.9$ & $0.6846^{*}$ \\
L-DOPA (mg/day) & $241.6 \pm 112.9$ & $431.8 \pm 202.8$ & $301.4 \pm 167.1$ & $0.0014^{*}$ \\
UPDRS part 3 & $16.1 \pm 9.2$ & $12.6 \pm 10.2$ & $15.0 \pm 9.5$ & $0.322^{*}$ \\
MMSE & $24.8 \pm 4.8$ & $27.0 \pm 3.1$ & $25.6 \pm 4.4$ & $0.1459^{*}$ \\
Apathy scale & $17.3 \pm 6.5$ & $12.6 \pm 3.9$ & $15.7 \pm 6.1$ & $0.0297^{*}$ \\
Apathy & $14(58.3 \%)$ & $3(25.0 \%)$ & $17(47.2 \%)$ & $0.1249^{\S}$ \\
\hline
\end{tabular}

Values are mean \pm SD, PPX: pramipexole, UPDRS: the unified Parkinson’s disease rating scale, MMSE: mini-mental state examination, *: MannWhitney U test, §: Fisher's exact test. 
apathy scale and UPDRS score. To examine which clinical factors contribute to the effects of PPX, we assessed the effects of age, gender, length of illness (months), UPDRS score, MMSE and daily dose of L-DOPA by means of logistic regression analysis. A value of $\mathrm{p}<0.05$ was considered statistically significant.

\section{Results}

Mean age, gender, length of illness, UPDRS and MMSE were not statistically different between the 2 groups. Daily amount of oral medication of L-DOPA was significantly larger in the non-PPX group than in the PPX group. Before PPX treatment, 14 of 24 (58\%) patients in the PPX group were diagnosed as having apathy (apathy scale of more than 16 at the baseline). In the non-PPX group (treated with only L-DOPA), 3 of 12 (25\%) patients had apathy. The prevalence of apathy was not statistically significantly different between the 2 groups (Table 1).

In the PPX group, apathy scale improved from $17.3 \pm 6.5$ (SD) at baseline to $15.0 \pm 5.9$ (SD) at week 4 (not significant) and to $13.8 \pm 4.7$ (SD) at week $8(\mathrm{p}<0.05)$. In the non-PPX group, apathy scale changed from 12.6 \pm 3.9 (SD) at baseline to $14.2 \pm 6.9$ (SD) at week 4 (not significant) and to $14.2 \pm 6.0$ (SD) at week 8 (not significant) (Figure 1, left panel). In the PPX group, UPDRS Part III (motor function) significantly improved from $16.1 \pm 9.2$ (SD) to $9.6 \pm 7.2$ (SD) at week 4 (p < 0.0001) and to $7.6 \pm 7.1$ (SD) at week 8 (p < 0.0001). In the non-PPX group, UPDRS Part III changed from $12.6 \pm 10.2$ (SD) to $13.6 \pm 10.8$ (SD) at week 4 (not significant) and to $11.1 \pm 9.2$ (SD) at week 8 (not significant) (Figure 1, right panel).

There were no correlations between changes in apathy score and UPDRS score or length of illness in either the PPX or the non-PPX group. All examined background factors (age, gender, length of illness, UPDRS score, MMSE score and daily dose of L-DOPA) had no influence on the change in apathy score in either the PPX or the non-PPX group. In the PPX group, the baseline score of the apathy scale was negatively correlated with the change of the apathy score at week $4(\mathrm{p}<0.001)$ and week 8 ( $\mathrm{p}<0.0001)$, indicating that PPX had greater ameliorating effects on patients with more severe apathy.

\section{Discussion}

Our results indicate that administration of PPX of $1.5 \mathrm{mg}$ daily together with L-DOPA improved apathy in PD patients within 8 weeks, compared with mono-therapy with L-DOPA. Möller et al. reported that PPX treatment

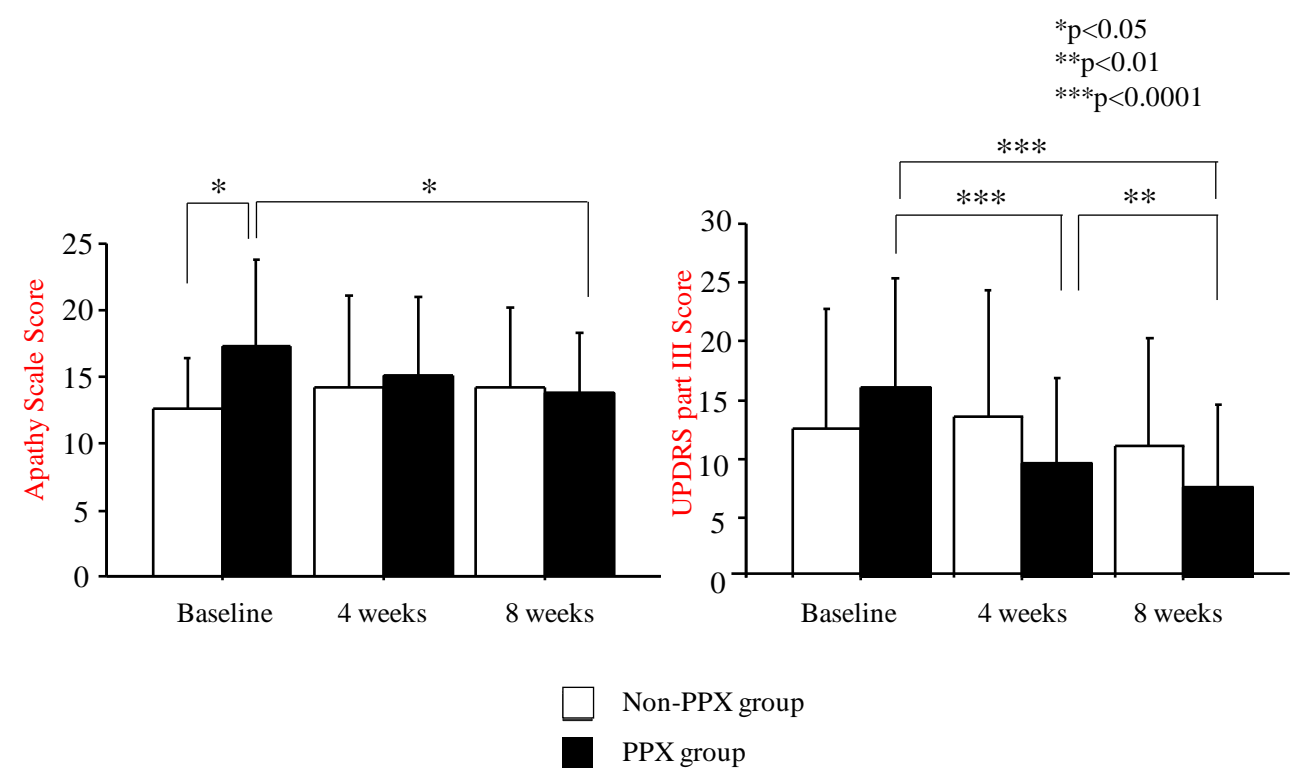

Figure 1. Left panel: The efficacy of pramipexole (PPX) on apathy in patients with Parkinson's disease (PD). Patients received PPX treatment plus L-DOPA (PPX group; 24 patients) or L-DOPA alone (non-PPX group, 12 patients). Right panel: The efficacy of pramipexole (PPX) on motor function (estimated by UPDRS part III) in patients with Parkinson's disease (PD). Patients received PPX treatment plus L-DOPA (PPX group; 24 patients) or L-DOPA alone (non-PPX group, 12 patients). 
improved UPDRS sum scores of part II and III by $30 \%$ and off-times by approximately 2.5 hours per day. It also significantly improved motivation/initiative and depression in the sub-items of UPDRS part I as a secondary outcome [7]. Lemke et al. reported that the frequency of depression, as well as motor deficits, was significantly reduced during treatment with PPX (mean dosage: $1.0 \pm 0.6 \mathrm{mg} /$ day) [8]. A meta-analysis of 7 clinical trials found improvement of motivation in 63.2\% of PD patients treated with PPX, but the assessments were conducted with the UPDRS part 1 item for motivation in all studies [9]. Thus, the current study is the first to report efficacy of PPX on apathy in PD as a primary outcome based on the apathy scale.

Apathy is defined as lack of motivation, manifested as diminished goal-directed behavior and cognition and decreased emotional engagement. It reduces the quality of life in PD patients with increasing functional dependency, as well as increasing the burden on caregivers [2] [4]. Dysfunction of the frontal-subcortical circuits, the mesocorticolimbic dopaminergic pathway, is thought to be a cardinal pathophysiological basis of apathy in PD, because a reduction of dopaminergic afferents to the ventral striatum disturbs normal interactions among the frontal lobe, caudate, anterior cingulate circuits and basal ganglia [3]. Functional change in the basal ganglia is a key factor for behavioral alterations in PD. A recent case study demonstrated that the administration of a dopamine $\mathrm{D}_{2} / 3$ receptor agonist was effective for the treatment of apathy after stroke [10]. We also reported a reduction of cerebral blood flow in the dorsolateral frontal lobe and basal ganglia in apathetic stroke patients [6] [11]. Decreased activities in these regions appear to contribute to the emergence of apathy symptoms.

The dopamine $\mathrm{D}_{3}$ receptor exists most densely in the mesolimbic system and may be involved in control of mood and behavior [12]. Preferential stimulation of the $\mathrm{D}_{3}$ receptor may explain the anti-depressive properties of dopamine agonists, and PPX (a $\mathrm{D}_{2} / \mathrm{D}_{3}$ agonist) exerts anti-depressive effects comparable with those of other anti-depressive drugs [13]. In two randomized placebo-controlled trials, PPX was effective as a mood stabilizer in treatment-resistant bipolar depression. The relationship between $\mathrm{D}_{2} / \mathrm{D}_{3}$ receptor and motivation has been confirmed by several studies. Apathy is a frequent complication after subthalamic nucleus stimulation of PD patients as a delayed dopamine withdrawal syndrome, and is often responsive to dopamine $D_{2} / D_{3}$ agonists [5]. A PET study also demonstrated that the dopamine transporter binding was reduced in the ventral striatum in PD patients with apathy [14]. These findings suggest that apathy in PD is profoundly associated with abnormality in dopamine transmission through $D_{2} / D_{3}$ receptor. Piribedil, another $D_{2} / D_{3}$ dopamine agonist, is widely used in France. The effectiveness of piribedil on apathy after subthalamic nucleus stimulation was first demonstrated in a placebo-controlled, randomized, double-blind trial [5].

Since apathy scale and motor function were improved after administration of PPX without any correlation between the two, the improvement of apathy was not due to improvement in motor function. As regards safety, no severe dopaminergic adverse events, such as hallucination (11.1\%), sleep attack (23\%), dizziness (10.6\%) and nausea (16.1\%) in previous report, were observed in our patients [7]. Starting with a low dose of PPX, followed by a careful increase, might have helped to avoid these side effects. A systematic review of the studies on PPX in mood disorders reported that the mean dose of PPX was $1.6 \mathrm{mg}$, indicating that PPX can exert a therapeutic effect at a relatively low dose. PPX at $0.5 \mathrm{mg}$ (week 4) did not show any effectiveness on apathy, but $\mathrm{PPX}$ at $1.5 \mathrm{mg}$ (week 8) reached the therapeutic range for apathy. Thus we consider that the appropriate therapeutic threshold of PPX for apathy is $1.5 \mathrm{mg}$ per a day [15].

Our result shows that the degree of improvement of apathy scale by PPX is dependent upon the severity of baseline apathy before the therapy. This is consistent with a meta-analysis of clinical studies for depression, which showed that initial severity of depression was related to the magnitude of treatment effects of anti-depressants [16]. Although we could not find any such reports dealing with apathy treatment, our current findings suggest that PPX could be useful for treating severe apathy in PD. In early PD who are not receiving levodopa or other dopamine agonists, PPX-treated subjects showed a significantly less development of dyskinesia (9.9\%) compared with levodopa (30.7\%) by one randomized controlled trial. PPX could be a candidate for early PD with apathy [17].

\section{Conclusion}

PPX may be effective for treating apathy as well as motor dysfunction in PD at the relative low dose of $1.5 \mathrm{mg}$ per day. It would be worthwhile to conduct a longer-term double-blind clinical trial to further examine the effectiveness of PPX on apathy in PD. 


\section{Disclosure}

The authors declare that they have no conflict of interest.

\section{References}

[1] Piercey, M.F., Hoffmann, W.E., Smith, M.W. and Hyslop, D.K. (1996) Inhibition of Dopamine Neuron Firing by Pramipexole, a Dopamine $\mathrm{D}_{3}$ Receptor-Preferring Agonist: Comparison to Other Dopamine Receptor Agonists. European Journal of Pharmacology, 312, 35-44. http://dx.doi.org/10.1016/0014-2999(96)00454-2

[2] Marin, R.S. (1991) Apathy: A Neuropsychiatric Syndrome. The Journal of Neuropsychiatry and Clinical Neurosciences, 3, 243-254.

[3] Martínez-Horta, S., Riba, J., de Bobadilla, R.F., Pagonabarraga, J., Pascual-Sedano, B., Antonijoan, R.M., et al. (2014) Apathy in Parkinson's Disease: Neurophysiological Evidence of Impaired Incentive Processing. The Journal of Neuroscience, 34, 5918-5926. http://dx.doi.org/10.1523/JNEUROSCI.0251-14.2014

[4] Pedersen, K.F., Larsen, J.P., Alves, G. and Aarsland, D. (2009) Prevalence and Clinical Correlates of Apathy in Parkinson's Disease: A Community-Based Study. Parkinsonism \& Related Disorders, 15, 295-299. http://dx.doi.org/10.1016/j.parkreldis.2008.07.006

[5] Thobois, S., Lhommée, E., Klinger, H., Ardouin, C., Schmitt, E., Bichon, A., et al. (2013) Parkinsonian Apathy Responds to Dopaminergic Stimulation of $\mathrm{D}_{2} / \mathrm{D}_{3}$ Receptors with Piribedil. Brain, 136, 1568-1577. http://dx.doi.org/10.1093/brain/awt067

[6] Okada, K., Kobayashi, S., Yamagata, S., Takahashi, K. and Yamaguchi, S. (1997) Poststroke Apathy and Regional Cerebral Blood Flow. Stroke, 28, 2437-2441. http://dx.doi.org/10.1161/01.STR.28.12.2437

[7] Möller, J.C., Oertel, W.H., Köster, J., Pezzoli, G. and Provinciali, L. (2005) Long-Term Efficacy and Safety of Pramipexole in Advanced Parkinson's Disease: Results from a European Multicenter Trial. Movement Disorders, 20, 602-610. http://dx.doi.org/10.1002/mds.20397

[8] Lemke, M.R., Brecht, H.M., Koester, J. and Reichmann, H. (2006) Effects of the Dopamine Agonist Pramipexole on Depression, Anhedonia and Motor Functioning in Parkinson’s Disease. Journal of the Neurological Sciences, 248, 266-270. http://dx.doi.org/10.1016/j.jns.2006.05.024

[9] Leentjens, A.F., Koester, J., Fruh, B., Shephard, D., Barone, P. and Houben, J.J. (2009) The Effect of Pramipexole on Mood and Motivational Symptoms in Parkinson’s Disease: A Meta-Analysis of Placebo-Controlled Studies. Clinical Therapeutics, 31, 89-98. http://dx.doi.org/10.1016/j.clinthera.2009.01.012

[10] Kohno, N., Abe, S., Toyoda, G., Oguro, H., Bokura, H. and Yamaguchi, S. (2010) Successful Treatment of Post-Stroke Apathy by the Dopamine Receptor Agonist Ropinirole. Journal of Clinical Neuroscience, 17, 804-806. http://dx.doi.org/10.1016/j.jocn.2009.09.043

[11] Onoda, K., Kuroda, Y., Yamamoto, Y., Abe, S., Oguro, H., Nagai, A., et al. (2011) Post-Stroke Apathy and Hypoperfusion in Basal Ganglia: SPECT Study. Cerebrovascular Diseases, 31, 6-11. http://dx.doi.org/10.1159/000319771

[12] Guttman, M. and Jaskolka, J. (2001) The Use of Pramipexole in Parkinson's Disease: Are Its Actions $D_{3}$ Mediated? Parkinsonism \& Related Disorders, 7, 231-234. http://dx.doi.org/10.1016/S1353-8020(00)00062-6

[13] Corrigan, M.H., Denahan, A.Q., Wright, C.E., Ragual, R.J. and Evans, D.L. (2000) Comparison of Pramipexole, Fluoxetine, and Placebo in Patients with Major Depression. Depress Anxiety, 11, 58-65. http://dx.doi.org/10.1002/(SICI)1520-6394(2000)11:2<58::AID-DA2>3.0.CO;2-H

[14] Remy, P., Doder, M., Lees, A., Turjanski, N. and Brooks, D. (2005) Depression in Parkinson’s Disease: Loss of Dopamine and Noradrenaline Innervation in the Limbic System. Brain, 128, 1314-1322. http://dx.doi.org/10.1093/brain/awh445

[15] Hori, H. and Kunugi, H. (2012) The Efficacy of Pramipexole, a Dopamine Receptor Agonist, as an Adjunctive Treatment in Treatment-Resistant Depression: An Open-Label Trial. The Scientific World Journal, 2012, Article ID: 372474. http://dx.doi.org/10.1100/2012/372474

[16] Bower, P., Kontopantelis, E., Sutton, A., Kendrick, T., Richards, D.A., Gilbody, S., et al. (2013) Influence of Initial Severity of Depression on Effectiveness of Low Intensity Interventions: Meta-Analysis of Individual Patient Data. $B M J, 346$, f540. http://dx.doi.org/10.1136/bmj.f540

[17] Parkinson Study Group (2000) Pramipexole vs. Levodopa as Initial Treatment for Parkinson Disease: A Randomized Controlled Trial. The Journal of the American Medical Association, 284, 1931-1938.

http://dx.doi.org/10.1001/jama.284.15.1931 
Scientific Research Publishing (SCIRP) is one of the largest Open Access journal publishers. It is currently publishing more than 200 open access, online, peer-reviewed journals covering a wide range of academic disciplines. SCIRP serves the worldwide academic communities and contributes to the progress and application of science with its publication.

Other selected journals from SCIRP are listed as below. Submit your manuscript to us via either submit@scirp.org or Online Submission Portal.
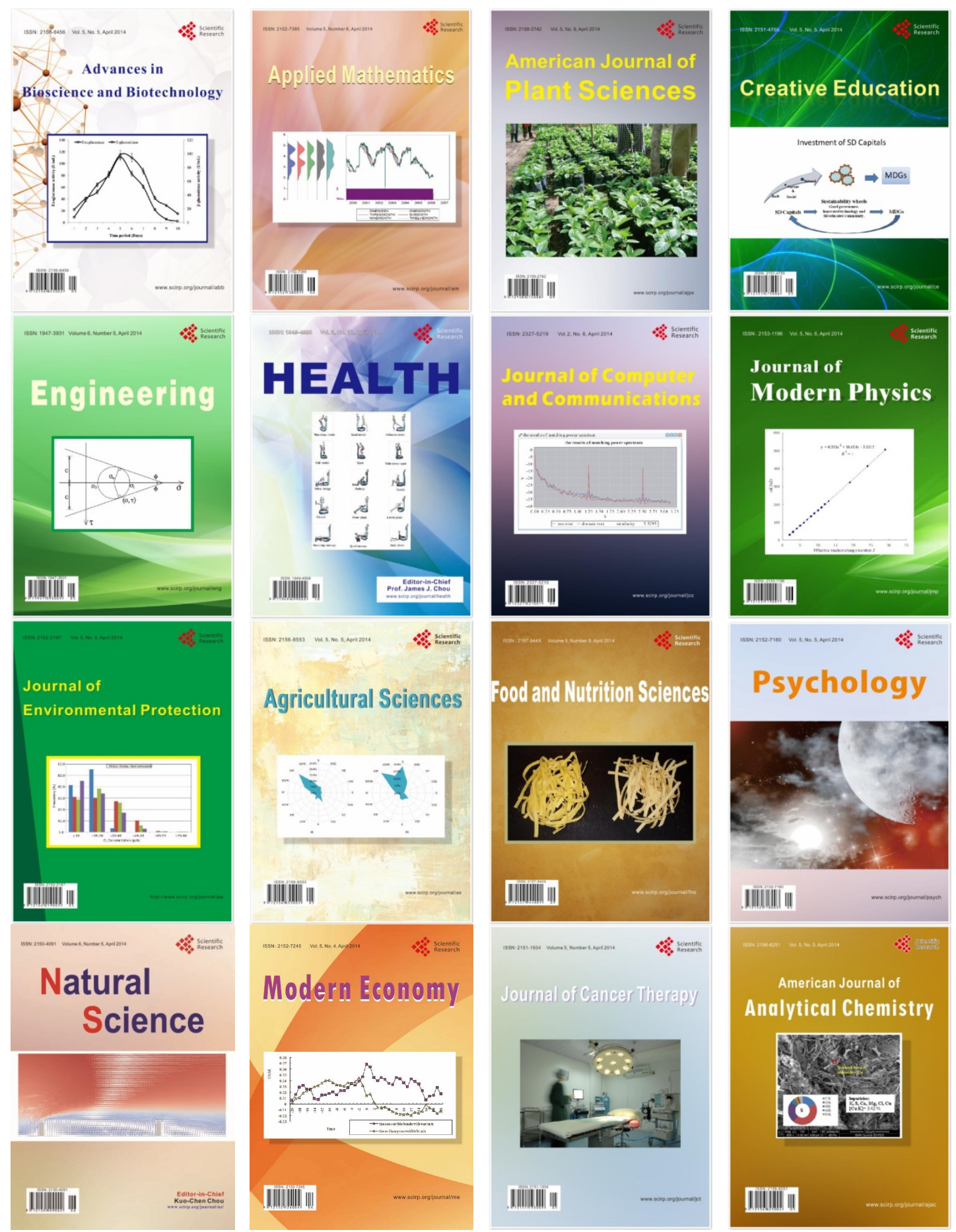